\title{
Peningkatan Kualitas Permukiman Suku Bajo Desa Popisi Kecamatan Bangggai Utara Kabupaten Banggai Laut (Studi Penangan Permukiman Masyarakat Suku Wajo)
}

Improving the Quality of the Bajo Tribe Statements Popisi Village, Sub-district Banggai Utara District Banggai Sea (Study of the Residential Handling of the Bajo Tribe)

\author{
Ayu Afrianti ${ }^{1}$, Batara Surya ${ }^{1,2}$, Kamran Aksa1 \\ ${ }^{1}$ Program Studi Perencanaan Wilayah dan Kota, Fakultas Teknik, Universitas Bosowa \\ 2 Program Studi Pascasarjana Perencanaan Wilayah dan Kota, Fakultas Teknik, Universitas Bosowa \\ Email : ayuafrilengkono84@gmai.com
}

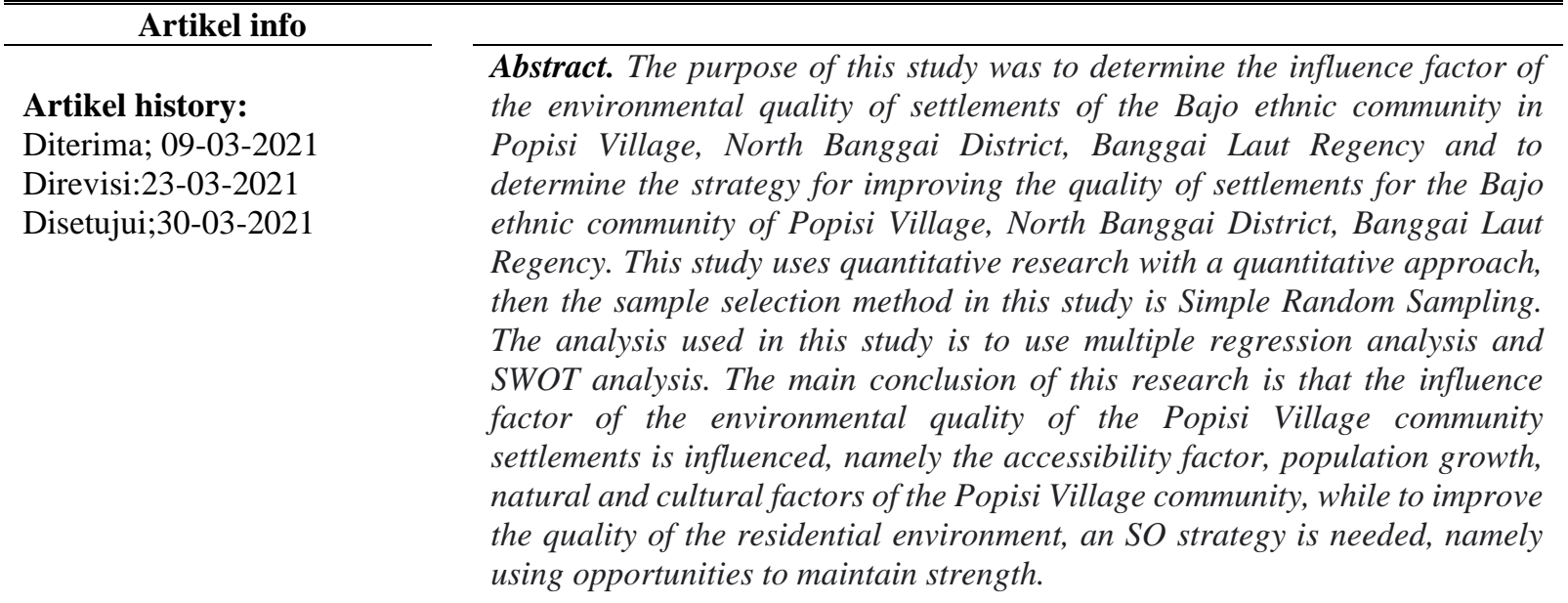

Abstrak. Tujuan penelitian ini ialah untuk mengetahui faktor pengaruh kualitas lingkungan permukiman masyarakat suku bajo Desa Popisi, Kecamatan Banggai Utara, Kabupaten Banggai Laut dan mengetahui strategi peningkatan kualitas permukiman masyarakat suku bajo Desa Popisi, Kecamatan Banggai Utara, Kabupaten Banggai Laut. Penelitian ini menggunakan penelitian kuantitatif dengan metode pendekatan kuantitatif, kemudian metode pemilihan sampel dalam penelitian ini ialah Simple Random Sampling. Analisis yang digunakan dalam penelitian ini ialah menggunakan analisis regresi berganda dan SWOT Analisis.. Kesimpulan utama dari penelitian ini ialah faktor pengaruh kualitas lingkungan permukiman masyarakat Desa Popisi dipengaruhi yaitu faktor aksesibilitas, pertumbuhan penduduk, faktor alam dan budaya masyarakat Desa Popisi sedangkan untuk peningkatan kualitas lingkungan permukiman dibutuhkan strategi SO yaitu menggunakan peluang untuk mempertahankan kekuatan.

Keywords: the settlement of the Bajo tribe, the environmental quality of the Bajo tribe settlement
Coresponden author:

Email : ayuafrilengkono84@gmai.com

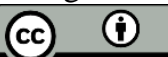

artikel dengan akses terbuka dibawah lisensi CC BY -4.0 


\section{PENDAHULUAN}

Settlement atau permukiman menurut Finch (1975) adalah kelompok satuan-satuan tempat tinggal atau kediaman manusia, mencakup fasilitasnya seperti bangunan rumah, serta jalur jalan, dan fasilitas lain yang digunakan sebagai sarana pelayanan manusia tersebut. Batasan ini mengarah pada arti permukiman sebagai kelompok satuan kediaman orang atau manusia pada suatu wilayah tidak hanya bangunan rumah tempat tinggal tetapi mencakup pula segala fasilitas yang diperlukan untuk menunjang penghuninya. Menurut Soemarwoto (1994) kualitas lingkungan adalah derajat kemampuan nyata suatu lingkungan untuk memenuhi perumahan yang baik yang dapat digunakan sebagai ruang tinggal bagi penghuninya dan terbentuk atas beberapa unsur, yaitu kondisi rumah sebagai tempat tinggal dan keadaan lingkungan rumah tersebut. Parameter untuk menentukan kualitas lingkungan permukiman sangat bermacam-macam. Kualitas lingkungan permukiman tidak lepas dari kualitas rumah-rumah yang ada di dalamnya, prasarana dasar dan sanitasi lingkungannya.

Masyarakat Suku Bajo dikenal sebagai masyarakat yang hidup (bermukim) di atas perairan. Adanya interaksi yang intensif antara masyarakat Suku Bajo dengan masyarakat yang hidup di darat menyebabkan terjadinya adopsi pola budaya oleh masyarakat Suku Bajo, termasuk pola permukiman menetap di pinggir pantai hingga bermukim di muara sungai. Tempat tinggal atau rumah Suku Bajo terletak di tepi laut, dan ada beberapa yang berada di atas permukaan air laut. Hal ini tidak lepas dari tradisi Suku Bajo yang identik dengan kehidupan laut dan mempunyai mata pencaharian utama sebagai nelayan (Ridwan \& Giyarsih, 2012).

Masyarakat Bajo adalah masyarakat nelayan yang hidup, tumbuh dan berkembang di wilayah perairan pesisir, yang memulai kehidupannya dengan mengembara di lautan dan melakukan segala aktifitasnya di atas perahu hingga bermukim di atas air. Hal ini dijalani sejak nenek moyang mereka yang mememiliki tempat tinggal di atas perahu (sampan) yang sangat sederhana dengan bentuk atap yang menyerupai rumah dan memiliki fasilitas seadanya. Tempat tinggal tersebut masyarakat menamainya dengan sebutan bidok (perahu), kemudian membangun kampoh berfungsi sebagai tempat tinggal dan dijadikan sebagai sarana dalam mencari nafkah untuk memenuhi kebutuhan hidup sehari-hari.

Secara kultural, menjaga kekayaan laut adalah salah satu sifat yang diemban oleh suku bajo. Dengan kearifannya mereka mampu menyesuaikan diri dengan ganasnya lautan. Laut adalah tumpuan hidup bagi masyarakat suku Bajo, yang membuat mereka tidak bisa menjauh dari lautan. Hunian tempat tinggal masyarakat suku Bajo pula berada pada permukaan laut yang dibuat secara terapung diatas batu karang yang telah mati dan pondasinya terbuat dari kayu. Bahkan mereka menjadikan perahu-perahu mereka adalah rumah untuk melakukan aktivitasnya sehari-hari.

Namun hari ini, masyarakat suku Bajo perlahan-lahan mengalami perubahan dalam konteks tempat tinggal mereka yang sudah menepi di wilayah daratan, dan juga telah memperhatikan dunia pendidikan. Perkembangan zaman membuat suku Bajo yang sebelumnya hidup mengembara (nomaden) menjadi tinggal menetap di wilayah pesisir dan laut sekitar. Sudah banyak suku Bajo yang menyebar di sepanjang pantai dan membuat rumah permanen sebagai tempat tinggal.

Berdasarkan Peraturan Menteri PUPR Nomo 02/PRT/M/2016 tentang Peningkatan Kualitas Terhadap Perumahan Kumuh dan Permukiman Kumuh, tipologi perumahan kumuh dan permukiman kumuh terbagi atas lima yaitu permukiman kumuh atas air, permukiman kumuh tepi air, permukiman kumuh perbukitan, permukiman kumuh rawan bencana, dan permukiman kumuh dataran rendah. Dari 5 tipologi kumuh diatas dengan melihat letak geografis dan kondisi yang ada dilokasi penelitian permukiman suku bajo Desa Popisi termasuk dalam tipologi kumuh atas air karena permukiman masyarakat yang berada diatas air dan tipe bangunan yaitu tipe panggung. Adapun karakteristik permukiman kekumuhan yaitu merupakan a) satuan entitas perumahan dan permukiman, yang mengalami degradasi kuallitas; b) kondisi bangunan memiliki kepadatan tinggi, tidak teratur dan tidak memenuhi syarat; c) kondisi sarana dan prasarana tidak memenuhi syarat.

Perkembangan permukiman saat ini begitu pesat seiring dengan perkembangan jumlah penduduk yang ada. Dengan berkembangnya permukiman masyarakat suku bajo, memudahkan masyarakat suku bajo untuk melakukan sosialisasi ataupun interaksi dengan masyarakat yang diluar suku bajo.

Faktor yang mempengaruhi kecenderungan masyarakat untuk berhuni dipinggiran sungai yaitu Aspek Ekonomi dan Aspek Politik berpengaruh bagi keberadaan permukiman ini. (Ariadi Abil, 2020), Jika perkembangan permukiman tidak diperhatikan atau diatur, maka dapat memberikan dampak buruk terhadap kualitas permukiman masyarakat suku bajo saat ini bahkan dapat berdampak buruk untuk kedepannya. Sehubungan dengan itu maka peneliti melakukan penelitian untuk melihat faktor apa yang mempengaruhi perkembangan kualitas permukiman Suku Bajo terhadap kondisi sosial ekonomi masyarakat di Desa Popisi. Perkembangan permukiman sangatlah berpengaruh dengan kualitas permukiman yang ada oleh karena itu di perlukan penanganan permukiman masyarakat Suku Bajo untuk perkembangan kualitas permukiman di daerah penelitian.

Sehingga melihat fenomena perkembangan permukiman suku bajo Desa Popisi berdasarkan uraian diatas maka dianggap perlu dilakukan penelitian yang berjudul tentang "Peningkatan Kualitas Permukiman Suku Bajo 
(studi penanganan permukiman masyarakat suku bajo)" agar melalui hasil penelitian ini dapat memberikan informasi kepada peneliti dan semua pihak tentang penanganan peningkatan kualitas lingkungan permukiman masyarakat suku bajo Desa Popisi, Kecamatan Banggai Utara, Kabupaten Banggai Laut.

\section{METODE}

\subsection{Jenis Data}

Data kuantitatif adalah jenis data yang dapat diukur (measurable) atau dihitung secara langsung sebagai variabel angka atau bilangan. Sedangkan Data kualitatif adalah data dari penjelasan kata verbal tidak dapat dianalisis dalam bentuk bilangan atau angka. Jenis dan Sumber Data yang digunalan dalam penelitian ini adalah data Kuantitatif dan Kualitatif, yaitu :
a. Aksesibilitas
b. Moda Transportasi
c. Pertumbuhan Penduduk
d. Kegiatan Masyarakat
e. Faktor Alam
f. Budaya Masyarakat

\subsection{Teknik Pengumpulan Data}

Pengumpulan data primer dalam penelitian ini dilakukan dengan observasi, wawancara dan dokumentasi. Untuk sumber data yang diklasifikasikan kedalam sumber data primer dalam penelitian ini adalah :
a. Aksesibilitas
b. Moda Transportasi
c. Pertumbuhan Penduduk
d. Kegiatan Masyarakat
e. Faktor Alam
f. Budaya Masyarakat

\subsection{Variabel Penelitian}

Variabel yang digunakan dalam penelitian ini, yaitu :

Tabel 1. Variabel Penelitian

\begin{tabular}{cl}
\hline Variabel Y & \multicolumn{1}{c}{ Variabel X } \\
\hline & X1: Aksesibilitas \\
Kualitas Lingkungan Masyarakat & X2: Moda Transportasi \\
& X3 : Pertumbuhan Penduduk \\
X4 : Kegiatan Masyarakat & X5 : Faktor Alam \\
X6: Budaya Masyarakat \\
\hline
\end{tabular}

\subsection{Metode Analisis}

Metode analisis yang digunakan dalam penelitian ini yaitu dengan metode analisis yang digunakan yaitu Regresi Berganda. Analisis regresi pada dasarnya adalah studi mengetahui ketergantungan variabel dependen (terikat) dengan satu atau lebih variabel independen (variabel penjelasan/bebas), dengan tujuan untuk mengestimasi dan/atau memprediksi rata-rata populasi atau nilai-nilai variabel dependen berdesarkan nilai variabel independen yang diketahui (Ghozali, 2005). Untuk regresi yang variabel independennya terdiri atas dua atau lebih, regresinya disebut juga regresi berganda. Oleh karena variabel independen diatas mempunyai variabel yang lebih dari dua, maka regresi dalam penelitian ini disebut regresi berganda. Persamaan regresi berganda yang digunakan dalam penelitian ini adalah :

a) Analisis Regresi Berganda

$\mathrm{Y}=\mathrm{a}+\mathrm{b}_{1} \mathrm{X}_{1}+\mathrm{b}_{2} \mathrm{X}_{2}+\mathrm{b}_{3} \mathrm{X}_{3}+\mathrm{b}_{4} \mathrm{X}_{4}$

Dimana :

$\mathrm{Y}=$ subjek dalam variabel dependen yang diprediksikan

$\mathrm{a}=$ harga $\mathrm{Y}$ bila $\mathrm{X}=0$ (herga konstan) 
$\mathrm{b}=$ angka arah atau koefisien regresi, yang menunjukan angka peningkatan ataupun penurunan variabel dependen yang didasarkan pada variabel independen.

$\mathrm{X}=$ subjek pada variabel Independen yang mempunyai nilai tertentu. Secara teknis harga b merupakan tangen dari (perbandingan) antara.

\section{b) Analisis SWOT}

Menurut Rangkuti (2009) proses penyusunan perencanaan strategis melalui tiga tahap, yakni tahap pengumpulan data, tahap analisis, dan tahap pengambilan keputusan. Sebelum melakukan proses identifikasi, terlebih dahulu disepakati basis analisis stakeholders yang berhubungan dengan pihak internal maupun eksternal. Dalam kajian ini, yang dikategorikan sebagai pihak internal adalah stakeholders Pemerintahan Desa Popisi Kecamatan Banggai Utara Kabupaten Banggai Laut dan masyaraka Suku Bajo sedangkan pihak eksternal adalah pemerintah pusat, provinsi dan masyarakat atau pengusaha di luar Kabupaten Banggai Laut. Hal ini dilakukan sehingga dapat memudahkan dalam melakukan analisis faktor internal dan eksternal.

\section{HASIL DAN PEMBAHASAN}

\subsection{Analisis Uji F}

Uji f digunakan untuk menguji pengaruh simultan jumlah populasi aksesibilitas (X1), moda transportasi (X2), pertumbuhan penduduk (X3), kegiatan masyarakat (X4), faktor alam (X5), budaya masyarakat (X6) terhadap kualitas lingkungan permukiman $(\mathrm{Y})$. uji ini dilakukan dengan melihat kolom $\mathrm{f}$. dapat dilihat pada tabel berikut ini :

Tabel 2. Hasil Uji F

\begin{tabular}{|c|c|c|c|c|c|c|}
\hline \multicolumn{7}{|c|}{$A N O V A^{b}$} \\
\hline & Model & Sum of Squares & $D f$ & Mean Square & $F$ & Sig. \\
\hline \multirow[t]{3}{*}{1} & Regression & 140.711 & 5 & 46.906 & 13.390 & $.000^{\mathrm{a}}$ \\
\hline & Residual & 574.393 & 94 & 6.111 & & \\
\hline & Total & 574.393 & 99 & & & \\
\hline
\end{tabular}

a. Predictors: (Constant), aksesibilitas, moda transportasi, pertumbuhan penduduk, kegiatan masyarakat, faktor alam, budaya masyarakat

b. Dependent Variable: Unstandardized Residual

Sumber: Hasil pengolahan data primer, 2020

Berdasarkan hasil pengujian pada tabel 4.9 dapat dilihat nilai fhitung pada kolom $\mathrm{F}$ yaknik 13.390. untuk $\mathrm{ftabel}=\mathrm{f}(\mathrm{k} ; \mathrm{n}-\mathrm{k}),=\mathrm{f}(6 ; 137-6) .=\mathrm{f}(6 ; 131)=2.44$. sehingga $\mathrm{f}_{\text {hitung }}>\mathrm{f}_{\text {tabel }}$ atau 13.390>2.44 maka Hasil ditolak. Hal ini menunjukan bahwa jummlah populasi aksesibilitas, moda transportasi, pertumbuhan penduduk, kegiatan masyarakar, faktor alam, dan budaya masyarakat secara simultan berpengaruh terhadap kualitas lingkungan permukiman. Demikian bahwa kualitas lingkungan permukiman dipengaruhi oleh aksesibilitas, moda transportasi, pertumbuhan penduduk, kegiatan masyarakat, faktor alam, dan budaya masyarakat dapat diterima.

\subsection{Analisis Uji T}

Uji t digunakan untuk menguji pengaruh secara parsial jumlah populasi aksesibilitas (X1), moda transportasi (X2), pertumbuhan penduduk (X3), kegiatan masyarakat (X4), faktor alam (X5), budaya masyarakat (X6) terhadap kualitas lingkungan permukiman $(\mathrm{Y})$. uji ini dilakukan dengan melihat kolom t pada masing-maasing variabel independent, dapat dilihat pada tabel berikut ini :

Tabel 3. Uji T

\begin{tabular}{|c|c|c|c|c|c|c|}
\hline \multicolumn{7}{|c|}{ Coefficients $^{a}$} \\
\hline & \multirow{2}{*}{ Model } & \multicolumn{2}{|c|}{ Unstandardized Coefficients } & \multirow{2}{*}{$\begin{array}{c}\text { Standardized } \\
\text { Coefficients }\end{array}$} & \multirow[t]{2}{*}{$t$} & \multirow[t]{2}{*}{ Sig. } \\
\hline & & B & Std. Error & & & \\
\hline \multirow[t]{8}{*}{1} & (Constant) & 1.260 & 2.340 & & 2.539 & .012 \\
\hline & Aksesibilitas & .027 & .147 & .020 & 2.187 & .017 \\
\hline & Moda Transportasi & -.101 & .166 & .085 & 1.787 & .019 \\
\hline & Pertumbuhan & .427 & .170 & .355 & 2.515 & .014 \\
\hline & Penduduk & & & & & \\
\hline & Kegiatan masyarakat & .220 & .146 & .186 & 1.788 & .018 \\
\hline & Faktor Alam & .358 & .101 & .332 & 3.534 & .001 \\
\hline & Budaya Masyarakat & .358 & .101 & .332 & 3.534 & .002 \\
\hline
\end{tabular}

a. Dependent Variable: Kualitas Lingkungan 
Ayu Afrianti, Batara Suryai, Kamran Aksa/ Journal of Urban and Regional Spatial. Vol 01 No 02. Hal 140-146

Berdasarkan tabel 4.10 dengan mengamati baris kolom t. maka diperoleh hasil sebagai berikut :

$$
\begin{aligned}
& \mathrm{T}_{\text {tabel }}=\mathrm{t}(\alpha / 2: \mathrm{n}-\mathrm{k}-1) \\
& \mathrm{T}_{\text {tabel }}=\mathrm{t}(0,05 / 2: 137-6-1) \\
& \mathrm{T}_{\text {tabel }}=\mathrm{t}(0,025: 130) \\
& \mathrm{T}_{\text {tabel }}=1,978
\end{aligned}
$$

a. Pengaruh Variabel Aksesibilitas (X1) Terhadap Kualitas Lingkungan Permukiman (Y)

Nilai signifikansi variabel aksesibilitas (X1), adalah 0,017 lebih kecil dari 0,05. Serta nilai t-hitung yaitu 2,187 lebih besar dari nilai t-tabel yaitu 1,978 artinya ada pengaruh yang signifikan antara aksesibilitas (X1) terhadap kulitas lingkungan permukiman (Y).

b. Pengaruh Variabel Moda Transportasi (X2) Terhadap Kualitas Lingkungan Permukiman (Y)

Nilai signifikansi variabel moda transportasi (X2) adalah 0,019 lebih kecil dari 0,05. Serta nilai t-hitung yaitu 1,787 lebih kecil dari nilai t-tabel yaitu 1,978 artinya tidak ada pengaruh yang signifikan antara transportasi (X2) terhadap kualitas lingkungan permukiman (Y).

c. Pengaruh Variabel Pertumbuhan Penduduk (X3) Terhadap Kualitas Lingkungan Permukiman (Y)

Nilai signifikansi variabel pertumbuhan penduduk (X3) adalah 0,014 lebih kecil dari 0,05. Serta nilai t-hitung yaitu 2,515 lebih besar dari nilai t-tabel yaitu 1,978 artinya ada pengaruh yang signifikan antara pertumbuhan penduduk (X3) terhadap kualitas lingkungan permukiman (Y).

d. Pengaruh Variabel Kegiatan Masyarakat (X4) Terhadap Kualitas Lingkungan Permukiman (Y)

Nilai signifikansi variabel kegiatan masyarakat (X4) adalah 0,018 lebih kecil dari 0,05. Serta nilai t-hitung yaitu 1,788 lebih kecil dari nilai t-tabel yaitu 1,978 artinya tidak ada pengaruh yang signifikan antara kegiatan masyarakat (X4) terhadap kualitas lingkungan permukiman (Y).

e. Pengaruh Variabel Faktor Alam (X5) Terhadap Kualitas Lingkungan Permukiman (Y)

Nilai signifikansi variabel faktor alam (X5) adalah 0,001 lebih kecil dari 0,05. Serta nilai t-hitung yaitu 3,534 lebih besar dari nilai t-tabel yaitu 1,978 artinya ada pengaruh yang signifikan antara faktor alam (X5) terhadap kualitas lingkungan permukiman (Y).

f. Pengaruh Variabel Budaya Masyarakat (X6) Terhadap Kualitas Lingkungan Permukiman (Y)

Nilai signifikansi variabel budaya masayarakat (X6) adalah 0,001 lebih kecil dari 0,05. Serta nilai t-hitung yaitu 3,534 lebih besar dari nilai t-tabel yaitu 1,978 artinya ada pengaruh yang signifikan antara budaya

\begin{tabular}{|c|c|c|c|c|}
\hline No. & Faktor Internal Strengeth (Kekuatan) & Bobot & Rating & Skor \\
\hline 1 & Aksesibilitas & 0,21 & 3 & 0,63 \\
\hline 2 & Pertumbuhan penduduk & 0,29 & 4 & 1,16 \\
\hline 3 & Faktor alam & 0,29 & 4 & 1,16 \\
\hline 4 & Budaya masyarakat & 0,29 & 4 & 1,16 \\
\hline \multicolumn{2}{|r|}{ Jumlah } & & & 4,11 \\
\hline No & Faktor Internal Weakness (Kelemahan) & Bobot & Rating & Skor \\
\hline 1 & Moda transportasi & 0,50 & 2 & 1,00 \\
\hline 2 & Kegiatan masyarakat & 0,50 & 2 & 1,00 \\
\hline & Jumlah & & & 2,00 \\
\hline
\end{tabular}
masayarakat (X6) terhadap kualitas lingkungan permukiman (Y).

\subsection{Analisis SWOT}

Tabel 4. Nilai Skor IFAS

Sumber : Hasil Analisis, 2020 
Tabel 5. Nilai Skor EFAS

\begin{tabular}{clccc}
\hline No & \multicolumn{1}{c}{ Faktor Eksternal Opportunities (Peluang) } & Bobot & Rating & Skor \\
\hline 1 & Undang-undang No. 26 tahun 2007 tentang Penataan Ruang & 0,21 & 4 & 0,84 \\
2 & $\begin{array}{l}\text { Undang-undang No. 11 tahun 2009 tentang Kesejahteraan } \\
\text { Sosial }\end{array}$ & 0,14 & 3 & 0,42 \\
$\begin{array}{l}\text { Berdasarkan Perda RTRW Kab. Banggai Laut No. 9 tahun } \\
\text { 2015 yang dijabarkan bahwa pengembangan pusat kota dan } \\
\text { pusat pertumbuhan lainnya yang berlandaskan nilai-nilai } \\
\text { budaya banggai } \\
\text { Berdasarkan Perda RTRW Kab. Banggai Laut No. } 9 \text { tahun } \\
\text { 2015 yang dijabarkan bahwa Desa Popisis sebagai pusat } \\
\text { pelayanan lingkungan. }\end{array}$ & 0,21 & 0,21 & 4 \\
$\quad$ Jumlah & & 0,84 \\
\hline
\end{tabular}

Sumber : Hasil Analisis, 2020

Kesimpulan :

a. Penentuan titik koordinat X, (IFAS) hasil Kekuatan - Kelemahan

b. Penentuan titik koordinat Y, (EFAS) hasil Peluang - Ancaman

Koordinat $X=4,11-2,00=2,11$

Koordinat $\mathrm{Y}=3,78-1,26=2,52$

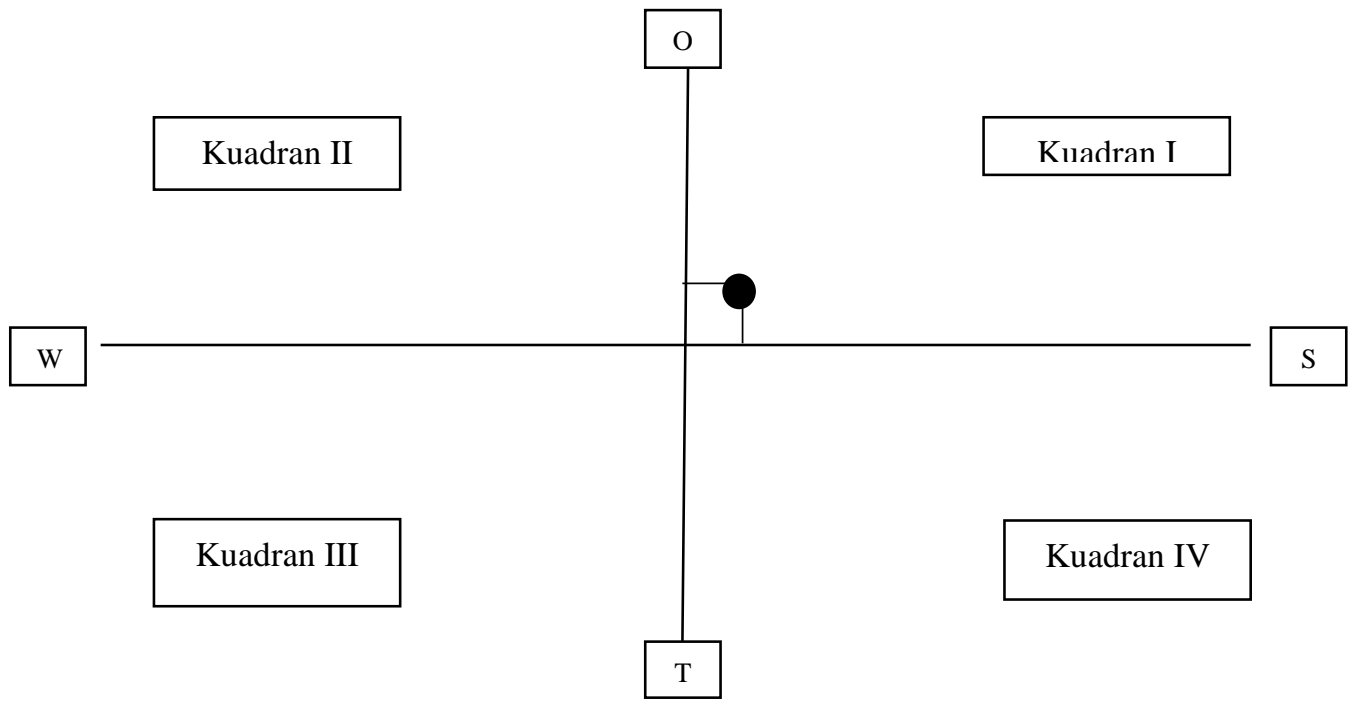

Gambar 1. Kuadran SWOT, Hasil Analisis 2020

Posisi berada pada sumbu $X=2,11$ dan sumbu $Y=2,52$, jadi posisi pada kuadran I. Strategi yang digunakan dan diprioritaskan yaitu Strategi SO. Rumusan strateginya adalah memanfaatkan peluang untuk mempertahankann kekuatan.

a. Mensosialisasikan kebijakan pemerintah yaitu Undang-undang nomor 26 tahun 2007 tentang penataan ruang untuk mempertahankan dan meningkatkan kualitas aksesibilitas yang ada.

b. Mensosialisasikan kebijakan pemerintah yaitu Undang-undang nomor 11 tahun 2009 tentang kesejahteraan sosial untuk menjaga dan meningkatkan kualitas pertumbuhan penduduk.

c. Mensosialisasikan kebijakan daerah yaitu Perda RTRW Kabupaten Banggai Laut nomor 9 tahun 2015 yang dijabarkan bahwa pengembangan pusat kota dan pusat pertumbuhan lainnya yang berdasarkan nilai-nilai budaya Banggai untuk mempertahankan dan meningkatkan kualitas budaya masyarakat suku bajo.

d. Mensosialisasikan kebijakan daerah yaitu Perda RTRW Kabupaten Banggai Laut nomor 9 tahun 2015 yang dijabarkan bahwa Desa Popisi sebagai Pusat Pelayanan Lingkungn (PPL) untuk mempertahankan dan meningkkatkan kualitas faktor alam suku bajo Desa Popisi. 


\section{KESIMPULAN}

Setelah melakukan beberapa tahapan dari proses penelitian Peningkatan Kualitas Permukiman Suku Bajo Desa Popisi, Kecamatan Banggai Utara, Kabupaten Banggai Laut (Studi Penanganan Permukiman Masyarakat Suku Bajo), menghasilkan pembahasan dan analisis yang telah dilakukan sebelumnya maka peneliti dapat menarik beberapa kesimpulan antara lain yaitu faktor yang mempengaruhi kualitas lingkungan permukiman masyarakat Suku Bajo Desa Popisi yaitu aksesibilitas, pertumbuhan penduduk, faktor alam dan budaya masyarakat. Dan strategi untuk peningkatan kualitas permukiman masyarakat suku bajo Desa Popisi adalah Mensosialisasikan kebijakan pemerintah yaitu Undang-undang nomor 26 tahun 2007 tentang penataan ruang untuk mempertahankan dan meningkatkan kualitas aksesibilitas yang ada; Mensosialisasikan kebijakan pemerintah yaitu Undang-undang nomor 11 tahun 2009 tentang kesejahteraan sosial untuk menjaga dan meningkatkan kualitas pertumbuhan penduduk; Mensosialisasikan kebijakan daerah yaitu Perda RTRW Kabupaten Banggai Laut nomor 9 tahun 2015 yang dijabarkan bahwa pengembangan pusat kota dan pusat pertumbuhan lainnya yang berdasarkan nilai-nilai budaya Banggai untuk mempertahankan dan meningkatkan kualitas budaya masyarakat suku bajo; Mensosialisasikan kebijakan daerah yaitu Perda RTRW Kabupaten Banggai Laut nomor 9 tahun 2015 yang dijabarkan bahwa Desa Popisi sebagai Pusat Pelayanan Lingkungn (PPL) untuk mempertahankan dan meningkatkan kualitas faktor alam suku bajo Desa Popisi

\section{DAFTAR PUSTAKA}

Abil, A., Latief, R., \& Yahya, I. (2020). Strategi Pengendalian Perkembangan Permukiman Disepanjang Sungai Tallo Kelurahan Rapokalling Kecamatan Tallo Kota Makassar. Journal of Urban Planning Studies, 1(1), 098104.

Finch, Verno C. 1957. Elements of Geography. New York: McGraw Hill Book Company.

Otto Soemarwoto. 1994. Ekologi Lingkungan dan Pembangunan, Djambatan. Jakarta.

Freddy Rangkuti. 20014. ANALISIS SWOT: Teknik Membedah Kasus Bisnis. PT Gramedia Pustaka Utama, Jakarta

Ghozali, Imam. 2005. Aplikasi Analisis Multivariate dengan SPSS. Semarang: Badan Penerbit UNDIP.

U. Ridwan, and S. Giyarsih, "Kualitas Lingkungan Permukiman Masyarakat Suku Bajo di Daerah yang Berkarakter Pinggiran Kota dan Daerah Berkarakter Pedesaan di Kabupaten Muna," Jurnal Pembangunan Wilayah dan Kota, vol. 8, no. 2, pp. 118-125, Jun. 2012.

Peraturan Menteri PUPR. (2016). tentang Peningkatan Kualitas Terhadap Perumahan Kumuh dan Permukiman Kumuh (Nomor 02/PRT/M/2016). Sekretariat Negara: Indonesia 